\title{
Análisis productivo y reproductivo de vacas lecheras Holstein, Pardo Suizo y sus cruzas en un sistema a pastoreo
}

\author{
Vallone, R.'; Camiletti, E. ; Exner, M.²; Mancuso, W.3; Marini, P. ${ }^{1}$
}

${ }^{1}$ Facultad de Ciencias Veterinarias, Universidad Nacional de Rosario, Ovidio Lagos y Ruta 33, Casilda (2170), Santa Fe, Argentina. ${ }^{2}$ Escuela Agrotécnica Las Delicias, Paraná, Entre Ríos, Argentina. ${ }^{3}$ Instituto Nacional de Tecnología Agropecuaria (INTA), Oro Verde, Entre Ríos, Argentina. E-mail: pmarini@fveter.unr.edu.ar

\begin{abstract}
Resumen
Vallone, R.; Camiletti, E.; Exner, M.; Mancuso, W.; Marini, P.: Análisis productivo y reproductivo de vacas lecheras Holstein, Pardo Suizo y sus cruzas en un sistema a pastoreo. Rev. vet. 25: 1, 40-44, 2014. El objetivo del trabajo fue comparar aspectos productivos y reproductivos de vacas pertenecientes a tres genotipos lecheros, en un sistema a pastoreo con suplementación de Entre Ríos, Argentina. Se analizaron datos retrospectivos del período 2007-2013 para lactancias de vacas primíparas y multíparas pertenecientes a dos razas lecheras y su primer cruza: Holstein $(\mathrm{H})$, Pardo Suizo (P) y vacas $\mathrm{H} x$ toros $\mathrm{P}(\mathrm{F} 1)$. Las vacas primíparas presentaron diferentes pesos al parto según el genotipo considerado, no así las multíparas. La edad al primer parto fue menor en F1 que en $\mathrm{H}$, sin diferenciarse de P. F1 fue uno de los genotipos con menor intervalo parto-concepción (ipc) y P mostró los mayores. El número de servicios por preñez y los días en lactancia acompañaron en general la tendencia del ipc, con alta variabilidad dentro de cada genotipo. La producción de leche fue mayor de 6.000 litros en primíparas y mayor de 7.000 litros en multíparas, llegando a 8.027 litros en el genotipo $\mathrm{H}$. La producción de grasa butirosa, proteína total y sólidos totales resultó muy similar entre genotipos. Para el sistema y las lactancias consideradas, las variaciones dentro de cada genotipo no permitieron comparar adecuadamente su respuesta al ambiente y manejo del sistema, aunque al primer parto las vacas $\mathrm{H}$ fueron más altas y pesadas y produjeron más leche, en tanto las cruzas F1 en la primera lactancia presentaron mejores respuestas reproductivas, con similares producciones de grasa, proteína y sólidos totales que las razas puras. Por ello, puede considerarse que en este sistema las vacas F1 logran una producción de leche aceptable, especialmente en sólidos totales, con mejores respuestas reproductivas. Es necesario analizar información sobre mayor número de lactancias y/o animales para seleccionar adecuadamente los genotipos mejor adaptados a este ambiente y sistema productivo.
\end{abstract}

Palabras clave: vaca lechera, genotipos, sistema a pastoreo, reproducción, producción de leche.

\begin{abstract}
Vallone, R.; Camiletti, E.; Exner, M.; Mancuso, W.; Marini, P.: Analysis of production and reproduction of Holstein, Brown Swiss and their crossbreed dairy cows in a grazing system. Rev. vet. 25: 1, 40-44, 2014. This work aims to conduct a comparative analysis of productive and reproductive aspects of cows belonging to three dairy genotypes, in a grazing system with supplement in Entre Ríos, Argentina. Retrospective data were analyzed for the 2007-2013 period considering lactations of primiparous and multiparous cows from two dairy breeds and their first crosses: Holstein (H), Brown Swiss (P) and F1 (Brown Swiss cows $\mathrm{x}$ Holstein bulls). Primiparous cows had different birth weights considering genotype, but multiparous did not. The age at first calving was lower for F1 cows compared to $\mathrm{H}$, without difference with P. F1 was the genotype with lowest birth-conception interval (ipc) while $P$ showed the highest. The number of services per pregnancy and lactation days accompanied ipc trend, with high variability within each genotype. Milk production was above 6,000 liters

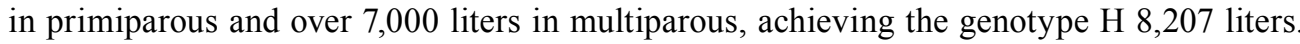
Productions of butirose fat, total protein and total solids were very similar among genotypes. For this system and the considered lactations, the variations among each genotype do not allow to adequately explain the response to the environment and managing system, although at the first birth $\mathrm{H}$ cows were higher and heavier and produced more milk, while $\mathrm{F} 1$ in the first lactation showed better reproductive response, with similar fat, protein and total solids
\end{abstract}


to those of pure breed. For this system it can be stated that F1 cows have an acceptable milk production, specially considering total solids, with better reproductive responses. It is necessary to analyze information about higher number of lactations and / or animals to select adequately the genotypes better adapted to this environment and productive system.

Key words: dairy cow, genotypes, grazing system, reproduction, milk production.

\section{INTRODUCCIÓN}

La producción de leche en sistemas a pastoreo exige una visión totalizadora y sistémica, con un conocimiento de las interacciones entre sus elementos para comprender los mecanismos asociados a la productividad y eficiencia, así como para interpretar sus variaciones y adaptaciones a lo largo del tiempo. En este contexto se afirma que la elección de la raza o del cruzamiento está íntimamente ligada al resto del sistema de producción adoptado y por ello el genotipo animal seleccionado debe estar en armonía con los recursos alimenticios, la sanidad, el clima y el manejo, ya que las ventajas de uno u otro tipo de ganado dependen del ambiente en el cual se encuentran ${ }^{10}$.

El potencial genético de los animales se expresa en la medida que las condiciones ambientales lo permitan y éstas no modifican de forma directa la constitución genética del individuo, pero sí determinan la extensión con que se expresa ${ }^{11}$. Sin embargo, cuando se considera la respuesta animal a distintos ambientes, además de los efectos genéticos y ambientales, se detecta un efecto adicional causado por su interacción ${ }^{3}$. En el mismo sentido, se postula que la acción conjunta de los factores genéticos y no genéticos, así como su interacción, influyen directamente sobre el comportamiento productivo y reproductivo del ganado de leche y carne ${ }^{9}$.

El modelo de producción lechero predominante en Argentina se basa en la raza Holando Argentino, con fuerte absorción desde mediados de los años 90 con el Holstein Americano y la tendencia general de los productores ha sido seleccionar animales dentro de esta raza por mayor producción individual de leche ${ }^{11}$. Sin embargo, durante la última década, en numerosos establecimientos de la Provincia de Entre Ríos (Argentina) se han incorporado paulatinamente otros genotipos de ganado lechero en sistemas de base pastoril, conformando rodeos cruzas que presentarían mayor estabilidad en la producción y mejoras importantes en cuanto a indicadores reproductivos ${ }^{7}$.

La utilización del cruzamiento en la producción lechera, es una alternativa para mejorar la salud, la fertilidad y la supervivencia, porque las diferencias entre razas son mayores que dentro de ellas mismas, pudiéndose lograr mayores beneficios por efecto de la heterosis $\mathrm{y}$, de las razas alternativas a la Holstein ofrecidas con este objetivo, la Jersey es la más utilizada, seguida de la Pardo Suizo, que presentaría mejor equilibrio en la relación grasa/proteína con respecto a las otras dos, presentándose como una opción adecuada desde el punto de vista industrial y nutricional ${ }^{2}$.

Por otro lado, la raza Pardo Suizo puede ofrecer ventajas comparativas en producción de leche, sobre todo en ecosistemas adversos a la Holstein, debido a su mayor adaptación a temperaturas extremas, su mayor tendencia y adaptación al pastoreo, mayor sanidad de ubre y longevidad ${ }^{5}$. En Entre Ríos existe una cabaña dedicada al mejoramiento de esta raza y vasta experiencia productiva en base a la raza Pardo Suizo; recientemente se demostró que se producen niveles similares y con mayor contenido de sólidos que la raza Holstein en condiciones bajo pastoreo con suplementación ${ }^{6}$.

Se planteó así el objetivo de analizar el comportamiento productivo y reproductivo de vacas lecheras Holstein, Pardo Suizo y sus cruzas, en un sistema a pastoreo con suplementación estratégica, típico de la cuenca lechera de Entre Ríos, Argentina.

\section{MATERIAL Y MÉTODOS}

Se evaluaron 115 vacas primíparas y multíparas pertenecientes a la Escuela Agrotécnica "Las Delicias", establecimiento lechero ubicado en el oeste de la Provincia de Entre Ríos. Durante el período evaluado (2007-2013) operó con un promedio de 120 vacas en ordeño de raza Holstein, Pardo Suizo y cruzas F1 entre ambas. Los animales convivieron en una única instalación de ordeño, pastoreando las mismas pasturas y con igual asignación de forrajes conservados y concentrados.

En dicho sistema, se analizaron los datos retrospectivos de lactancias de vacas primíparas pertenecientes a tres genotipos lecheros: Holstein Americano-Canadiense ("H"); Pardo Suizo ("P") y hembras Holstein x toros Pardo Suizo ("F1"). Con igual metodología, se analizaron datos de vacas multíparas correspondientes a las dos razas puras, ya que no hubo F1 multíparas en producción en ese período.

Las variables productivas y reproductivas evaluadas fueron: peso al parto $(\mathrm{kg})$, días de edad al primer parto (epp), días de intervalo parto-concepción (ipc), número de servicios utilizados para la concepción (nsc), altura a la cadera $(\mathrm{cm})$, producción de leche ajustada a 305 días de lactancia (PL) en litros, grasa butirosa (GB), proteína total (PT) y sólidos totales (ST) en kg.

La alimentación promedio típica del período considerado (Tabla 1), se basó en diferentes aportes estacionales del pastoreo directo sobre pasturas polifíticas 
base alfalfa, heno de praderas base alfalfa, concentrado comercial durante el ordeño (del 13 o del 16\% de PB según requerimientos nutricionales) y ración en mezcla entregada mediante carro racionador fuera del tambo, la cual estuvo constituida por silaje de planta entera de maíz, grano de maíz molido, afrechillo de trigo, expeler de soja, sales minerales, diatomeas en polvo y suero líquido de leche (subproducto de la quesería del mismo establecimiento). En algún año en particular hubo algún aporte de otros alimentos, como pulpa de citrus, grano de cebada, verdeos de invierno o de verano, que no se consideraron relevantes para ser tenidos en cuenta para este trabajo.

Para visualizar los resultados de los efectos se obtuvieron los promedios y el error estándar para cada variable y se realizó la comparación de medias por test de Tukey-Kramer HSD $(p<0,05)$ de las diferentes variables productivas y reproductivas evaluadas. Para la variable nsc se obtuvieron la mediana y sus rangos y se la analizó a través del test Wilcoxon/ Kruskal-Wallis, en tanto para el análisis de la progresión de la preñez en relación a los días de lactancia, se aplicó para cada subgrupo la curva de supervivencia de Kaplan-Meier y se compararon entre sí con la prueba Log-rank (Mantel-Cox).

\section{RESULTADOS}

Peso vivo y altura a la cadera de vacas primíparas. En la Tabla 2 se observa que las vacas primíparas presentaron diferentes pesos al parto entre los genotipos estudiados, siendo $\mathrm{H}$ las más pesadas y $\mathrm{F} 1$ las más livianas. Para la variable "altura a la cadera", H reveló los mayores valores, con diferencias significativas respecto a los demás genotipos. Los genotipo P y F1 registraron similares valores de peso y altura a la cadera.

Peso vivo y altura a la cadera de vacas multíparas. Las vacas no mostraron diferencias significativas $(p \leq 0,05)$ tanto en el peso vivo al parto, con valores en $\mathrm{H}(708 \pm 49 \mathrm{~kg})$ y en $\mathrm{P}(695 \pm 40 \mathrm{~kg})$, como en la altura a la cadera, donde $\mathrm{H}$ alcanzó un promedio de $148 \pm 0,02$ cm y $\mathrm{P} 146 \pm 0,03 \mathrm{~cm}$.

Edad al primer parto, intervalo parto-concepción $y$ servicios por preñez. En base a la edad al primer parto (epp) observada, las vaquillonas de los tres genotipos llegaron a su primera preñez entre los 21 y 26 meses de edad, en tanto que las vacas $\mathrm{H}$ se atrasaron en relación a F1, ya que necesitaron en promedio 154 días más para llegar al primer parto. Los resultados del intervalo parto-concepción (ipc) muestran que los tres genotipos estuvieron muy por encima del óptimo (82 días) para lograr un ternero por año (Tabla 3), con diferencias signi-
Tabla 2. Peso al primer parto y altura de los tres genotipos estudiados en primera lactancia ( $\overline{\mathrm{x}} \pm \mathrm{DE})$.

\begin{tabular}{lcc}
\hline genotipo & peso $(\mathrm{kg})$ & altura $(\mathrm{cm})$ \\
\hline $\mathrm{H}(20)$ & $732 \pm 65 \mathrm{a}$ & $150 \pm 0,04 \mathrm{a}$ \\
$\mathrm{P}(18)$ & $685 \pm 61 \mathrm{ab}$ & $146 \pm 0,04 \mathrm{~b}$ \\
F1 (15) & $647 \pm 46 \mathrm{~b}$ & $146 \pm 0,04 \mathrm{~b}$ \\
\hline
\end{tabular}

H: Holstein, P: Pardo Suizo, F1: vacas H x toros P, $\bar{x}$ : media aritmética, DE: desvío estándar. Letras distintas indican diferencias significativas $(\mathrm{p} \leq 0,05)$.

Tabla 3. Edad al primer parto (epp) e intervalo partoconcepción (ipc), $\bar{x} \pm D E$. Número de servicios utilizados para la concepción (nsc), mediana y rangos, en vacas primíparas.

\begin{tabular}{lccc}
\hline genotipo & epp (días) & ipc (días) & nsc (veces) \\
\hline $\mathrm{H}(\mathrm{n}=20)$ & $1.059 \pm 97 \mathrm{a}$ & $208 \pm 96 \mathrm{ab}$ & $2(1-4)$ \\
$\mathrm{P}(\mathrm{n}=18)$ & $1.008 \pm 187 \mathrm{ab}$ & $274 \pm 175 \mathrm{a}$ & $2,5(1-13)$ \\
$\mathrm{F} 1(\mathrm{n}=15)$ & $905 \pm 191 \mathrm{~b}$ & $159 \pm 74 \mathrm{~b}$ & $1(1-5)$ \\
\hline
\end{tabular}

X: media aritmética, DE: desvío estándar; letras distintas indican diferencias significativas $(\mathrm{p} \leq 0,05)$. El nsc está expresado en mediana y rangos (datos no significativos).

ficativas entre ellos, ya que las vacas $\mathrm{P}$ tardaron el doble de días en quedar preñadas con relación a las vacas $\mathrm{F} 1$. El número de servicios utilizados para la concepción (nsc) mostró diferencias significativas y acompañó en general la tendencia del ipc, en donde el rango de genotipo P fue más alto que el de F1.

Tasa de preñez. Al analizar las tasas de preñez de los tres genotipos en relación a la progresión de los días de lactancia, se destaca que los tres genotipos no revelaron una buena performance reproductiva, debido a que a los 82 días las vacas $\mathrm{H}$ solo lograron un $10 \%$ de preñez, las vacas P $0 \%$ y las vacas F1 15,4\%. A los 157 días de lactación $\mathrm{H}$ acumuló $35 \%$ de preñez, P 29,4\% y F1 62\%. A los 210 días de lactación H reveló 55\%, P 41,2 \% y F1 77\% de preñez. 
Tabla 4. Intervalo parto-concepción (ipc) y número de servicios utilizados para la concepción (nsc) en ambos genotipos de vacas multíparas.

\begin{tabular}{lccc}
\hline genotipo & $\mathrm{H}(\mathrm{n}=33)$ & $\mathrm{P}(\mathrm{n}=29)$ & $\mathrm{p} \geq 0,05$ \\
\hline ipc (días) & $231 \pm 127$ & $212 \pm 95$ & $\mathrm{NS}$ \\
nsc (veces) & $2(1-6)$ & $3(1-6)$ & $\mathrm{NS}$ \\
\hline
\end{tabular}

ipc expresado en $\overline{\mathrm{X}} \pm \mathrm{DE}$; nsc formulado en mediana y rangos; NS indica diferencias no significativas.

Tabla 5. Producción de leche ajustada a 305 días de lactancia (PL), grasa butirosa (GB), proteína total (PT) y sólidos totales (ST) en vacas primíparas de los tres genotipos estudiados, $\overline{\mathrm{x}} \pm \mathrm{DE}$.

\begin{tabular}{lcccc}
\hline genotipo & PL (litros) & GB $(\mathrm{kg})$ & PT $(\mathrm{kg})$ & ST $(\mathrm{kg})$ \\
\hline $\mathrm{H}(\mathrm{n}=20)$ & $7.162 \pm 856 \mathrm{a}$ & $223 \pm 27 \mathrm{a}$ & $227 \pm 33 \mathrm{a}$ & $775 \pm 230 \mathrm{a}$ \\
$\mathrm{P}(\mathrm{n}=18)$ & $6.168 \pm 1.046 \mathrm{~b}$ & $217 \pm 33 \mathrm{a}$ & $217 \pm 39 \mathrm{a}$ & $801 \pm 98 \mathrm{a}$ \\
$\mathrm{F} 1(\mathrm{n}=15)$ & $6.743 \pm 1.048 \mathrm{ab}$ & $221 \pm 51 \mathrm{a}$ & $227 \pm 38 \mathrm{a}$ & $825 \pm 143 \mathrm{a}$ \\
\hline
\end{tabular}

Letras distintas indican diferencias significativas $(\mathrm{p} \leq 0,05)$.

Tabla 6. Producción de leche ajustada a 305 días de lactancia (PL), grasa butirosa (GB), proteína total (PT) y sólidos totales (ST) en vacas multíparas, $\overline{\mathrm{x}} \pm \mathrm{DE}$.

\begin{tabular}{lccc}
\hline variable & $\mathrm{H}(\mathrm{n}=33)$ & $\mathrm{P}(\mathrm{n}=29)$ & significación \\
\hline PL (litros) & $8.207 \pm 1.655$ & $7.141 \pm 1.294$ & $\mathrm{~ns}$ \\
GB $(\mathrm{kg})$ & $239 \pm 37$ & $239 \pm 38$ & $\mathrm{~ns}$ \\
PT $(\mathrm{kg})$ & $264 \pm 42$ & $243 \pm 43$ & $\mathrm{~ns}$ \\
ST $(\mathrm{kg})$ & $938 \pm 156$ & $846 \pm 180$ & $\mathrm{~ns}$ \\
\hline
\end{tabular}

ns: diferencia no significativa.

Intervalo parto-concepción y servicios por preñez en vacas multíparas. La Tabla 4 muestra que los resultados del intervalo parto-concepción (ipc) en ambos genotipos estuvieron por encima del óptimo requerido para lograr un ternero por año (82 días). No existieron diferencias entre ellos, siendo muy similares los lapsos que tardaron en quedar preñadas. Los números de servicios por preñez (nsc) también fueron altos.

Producción de leche, grasa, proteína y sólidos totales en vacas primíparas. En la Tabla 5 se observa que la producción de leche ajustada a los 305 días en lactancia de vacas de primer parto, muestra valores promedios por encima de 6.000 litros. Se destacaron las vacas $\mathrm{H}$ con 7.162 litros (23,5 litros por vaca y día), mientras que las vacas $\mathrm{P}$ revelaron la menor producción con 6.168 litros (20,2 litros por vaca y día) y F1 inscribió valores intermedios. La producción de GB, PT y ST fue muy similar entre genotipos, destacándose que los pesos de las proteínas igualaron o superaron a los pesos de grasa producidos en $\mathrm{H}, \mathrm{P}$ y $\mathrm{F} 1$.

Producción de leche, grasa, proteína y sólidos totales en vacas multíparas. En la Tabla 6 se observa que no hubo diferencias significativas entre las vacas $\mathrm{H}$ y $\mathrm{P}$ en producción de leche, GB, PT y ST y que en ambos genotipos se registraron amplios desvíos estándares para estas variables. Es de destacar que, al igual que en las vacas primíparas, los $\mathrm{kg}$ de proteína superaron a los $\mathrm{kg}$ de grasa producidos en ambas razas evaluadas.

\section{DISCUSIÓN}

Uno de los factores a tener en cuenta en la producción lechera son los requerimientos energéticos de las vacas para mantenimiento y producción. Se estima que, desde el nacimiento y hasta la quinta lactancia, los requerimientos de mantenimiento representan alrededor del $56 \%$ de los requerimientos totales, aún en vacas con elevada producción ${ }^{8}$. Además, los requerimientos de mantenimiento son función directa del peso metabólico del animal y por ende de su peso corporal, por lo cual lo ideal en sistemas a pastoreo sería producir leche con vacas de menor peso o tamaño que las actuales.

Sin embargo, la existencia de correlaciones genéticas entre tamaño corporal y caracteres productivos antagónicas a este objetivo, torna dificultoso lograrlo. Por un lado la existencia de correlaciones medias y de signo positivo entre el tamaño de la vaca y la producción de leche ${ }^{1}$, determina que la selección directa por producción genere como respuesta correlacionada un aumento de tamaño e, inversamente, la disminución del tamaño de la vaca repercute negativamente sobre su producción. Por otro lado, la correlación genética entre el tamaño de la vaca y el consumo de alimento es también alta y positiva ${ }^{13}$, de manera tal que esas vacas de mayor tamaño tienen mayor consumo. Estas relaciones explican las correlaciones negativas, aunque bajas, informadas entre tamaño de la vaca y eficiencia de conversión ${ }^{12}$ a partir de la dilución del costo fijo de mantenimiento y de la disponibilidad de un mayor excedente para producción de leche.

Como se observa en los resultados obtenidos en el presente trabajo, dentro de las vacas primíparas el genotipo $\mathrm{H}$ mostró mayor peso que $\mathrm{F} 1$ y fue de mayor altura a la cadera con relación a P y F1. Para las vacas multíparas no se mantuvo la diferencia con las $\mathrm{P}$, pero la salvedad es que las vacas primíparas $\mathrm{H}$ son más pesadas y de mayor altura que las multíparas, por lo que estaría indicando que ambas variables siguen aumentado con las generaciones sucesivas para este genotipo en este sistema.

Estos hechos coinciden con resultados obtenidos en otras investigaciones, en las cuales no se encontraron diferencias en el peso vivo ni en la producción de leche de las vacas multíparas de las razas $\mathrm{H}$ y $\mathrm{P}$ puras ${ }^{6}$. Las dos razas puras y su cruza se comportaron en forma similar en cuanto a producción de GB, PT y ST, mostrando por otra parte una mayor producción de PT sobre GB, que podría vincularse al tipo de alimentación recibida, con alto porcentaje de concentrados en la dieta (entre 43 y $55 \%$ de la MS según la estación). Este equilibrio en producción de sólidos, que neutralizó las diferencias halladas en producción de leche entre las vacas primíparas $\mathrm{H}$ y $\mathrm{P}$, está vinculado con el mayor 
contenido de grasa y proteína en este último genotipo, en coincidencia con los resultados obtenidos por otros investigadores ${ }^{2,6}$.

Si se considera que la edad óptima al primer parto de vacas lecheras está entre los 22 y 27 meses, los resultados obtenidos en este trabajo señalan que todos los genotipos estudiados se acercaron a ese óptimo teórico, con primeros partos entre 21 y 26 meses, similares a los encontrados en vacas Holstein para sistemas presentes en Argentina. El manejo general de la recría de vaquillonas en este sistema podría entonces definirse como adecuado, ya que permite tener una vaca de primer parto a alrededor de los 24 meses, inseminándola a los 15 meses de edad. No obstante, las vacas F1 mostraron menor edad al primer parto que las vacas $\mathrm{H}$, con un promedio algo mayor a 21 meses, sin diferenciarse de las vacas $P$ pero con menor ipc que las vacas primerizas de esta raza.

Trabajos realizados en la misma región muestran que la cruza F1 de Holstein x Jersey parece tener un mejor comportamiento reproductivo en los sistemas a pastoreo ${ }^{4}$, hecho que podría atribuirse a la combinación de menores requerimientos de mantenimiento y al efecto heterótico puesto de manifiesto en las hembras cruzas. En los resultados encontrados en el presente trabajo, las vacas primíparas $\mathrm{P}$ y $\mathrm{H}$ revelaron mayor ipc que las vacas F1, en tanto que estas últimas estuvieron dentro de las que produjeron menor cantidad de leche, confirmando en tal sentido que, a mayor producción, se incrementa el ipc, independientemente del genotipo.

Puede concluirse que, en el sistema analizado y para las lactancias consideradas, las vacas $\mathrm{H}$ son más altas, más pesadas y producen más leche que los otros genotipos, diferencias que desaparecen en vacas de razas puras (H y P) con más de un parto. Por su parte, las cruzas F1 en la primera lactancia presentan mejores respuestas reproductivas, con similares producciones de GB, PB y ST, que las razas puras. Es necesario seguir analizando información sobre mayor número de lactancias y/o animales para poder mejorar la toma de decisiones al elegir los genotipos mejor adaptados al sistema productivo.

Agradecimientos. A los directivos, técnicos y personal no docente de la Escuela Agrotécnica Las Delicias, especialmente al Ing. Agr. Julio Butus, por su colaboración en la recopilación de información, discusión técnica y apoyo financiero.

\section{REFERENCIAS}

1. Ahlborn G, Dempfle L. 1992. Genetic parameters for milk production and body size in New Zealand HolsteinFriesian and Jersey. Livestock Prod Sci 31: 205-219.

2. Comerón E, Romero L, Cuatrín A, Maciel M. 2007. El efecto racial o genético. En: Manual de referencias técnicas para el logro de leche de calidad, 3ra. ed., Publ. INTA, Buenos Aires, p. 131-145.

3. Cruz CD, Regazzi AJ. 1994. Modelos biométricos aplicados ao melhoramento genético, $2^{\circ}$ ed., Edit. UFV, Viçosa, Brasil, 390 p.

4. Dutour EJ, Laborde D, Meikle A, Chilibroste P. 2010. Comportamiento reproductivo de vacas primíparas de diferentes grupos raciales en un sistema pastoril de producción de leche. Rev Arg Prod Anim 30: 85-108.

5. Gasque R. 2008. Enciclopedia Bovina, 1ra. ed., Publ.. Universidad Nacional Autónoma de México, México, 435 p.

6. Hofstetter MB. 2011. Comparación de producción, composición y rendimiento quesero de leche de vacas Holando Argentino y Pardo Suizo en Entre Ríos. Tesis Ing. Agr., Universidad Nacional de Entre Ríos, Argentina, 77 p.

7. Korver S. 1988. Genetic aspects of feed intake and feed efficiency in dairy cattle: a review. Livestock Prod Sci 20: $1-13$.

8. Krall E. 2003. Análisis de registros de predios comerciales. Ganado Holando, Jersey y sus cruzas para producción de leche. Rev Plan Agropec (Montevideo) 107: 31-35.

9. López O. 2002. Caracterización del comportamiento productivo y reproductivo de vacas Mambí de primera lactancia en un sistema silvopastoril. Tesis M. Sci., Estación Experimental Indio Hatuey, Matanzas, Cuba, $85 \mathrm{p}$.

10. Madalena FE. 2001. Consideraciones sobre modelos para predicción del desempeño de cruzamientos en bovinos. Arch Latinoam Prod Anim 9: 108-117.

11. Molinuevo HA. 2005. Selección de ganado lechero. En: Genética bovina y producción en pastoreo (INTA Ed.), Buenos Aires, p. 283-316.

12. Persaud P, Simm G, Hill WG. 1991. Genetic and phenotypic parameters for yield, food intake and efficiency of dairy cows fed ad libitum. 1. Estimates for total lactation measures and their relationship with liveweight traits. Anim Prod 52: 445-450

13. Veerkamp RF. 1996. Liveweight and feed intake in dairy cattle breeding goal. Proceed Internat Workshop Funct Traits in Cattle, Gembloux, Belgium. Interbull Bulletin 12: 173-178. 